\title{
Ore transport system selection for the Sintoukola potash project in the Republic of Congo
}

\author{
by P. Kluge*, D. Limpitlaw ${ }^{\dagger}$, and W. Swanepoel*
}

\section{Synopsis}

Material transport is one of the major components of a bulk mining system, and the selection of the most appropriate material transport system can have a significant bearing on the success of a mining project, particularly in Africa. This paper presents a three-criterion methodology for assessing a mine transport system. The three criteria are focused on operability, economic analysis (using the net present cost (NPC) methodology), and safety, health, and environment.

The methodology is demonstrated in a case study assessment of truck hauling $v s$ overland conveyor belt for the Sintoukola potash project in the Republic of Congo. The results show that for the given project configuration, an overland conveyor belt is preferred on the basis of all three criteria.

Keywords

bulk materials handling, ore transport system selection, overland conveyor belt, hauling, net present cost, Congo Brazzaville.

\section{Introduction}

The repeated performance of a number of fundamental processes lies at the heart of the mining process. These processes constitute the mining cycle (Singh and Saperstein, 1992). These fundamental processes are commonly referred to as 'unit operations' and comprise: fragmentation, loading, and haulage/transportation. There are also a number of auxiliary unit operations (such as site preparation and provision for services) but these are not discussed here. This paper deals with the selection of an ore transportation system for a planned potash mine in the Republic of Congo (Congo Brazzaville, RC).

\section{The Sintoukola potash project}

The Sintoukola potash project is a greenfield potash project located approximately $90 \mathrm{~km}$ north of the city of Pointe Noire in the RC. The project is located on the coastal plain between the Mayombé Mountains in the east and the Atlantic Ocean in the west. The potash deposit occurs within the Lower Cretaceous Loeme Evaporite Formation and is approximately 300 $\mathrm{m}$ below the surface. This evaporite sequence in the Congolese coastal basin comprises horizontal, undulating layers of salt. The targeted ore mineral is sylvinite $(\mathrm{KCl})$, although carnallitite $\left(\mathrm{KMgCl}_{3} \cdot 6 \mathrm{H}_{2} \mathrm{O}\right)$ is also present. The sylvinite is interbedded with halite ( $\mathrm{NaCl})$ and other salts.

The project consists of a planned underground board-and-pillar mine, a $35 \mathrm{~km}$ transport corridor to the coast, and a process plant and ship loading facility for export of potash to foreign markets. Underground access will be via a twin vertical shaft system. The mine and haulage/processing facilities are to be located in two of the administrative regions or sous-préfectures (Madingo Kayes and Loango) in the Kouilou Department.

The project currently consists of a measured and indicated resource of $573 \mathrm{Mt}$ of sylvinite, providing a sufficient reserve for a 23-year life of mine using a conventional underground mining method to produce $2 \mathrm{Mt} / \mathrm{a}$ of muriate of potash (MoP).

In order to achieve this production, 6.9 Mt/a (960 t/h) of run-of-mine (RoM) ore will be mined using a room-and-pillar method, utilizing continuous miners. The RoM ore will then be transported to a dedicated processing plant located $35 \mathrm{~km}$ from the mine at the coast. Due to the hydrophilic nature of the salts, the ore needs to be kept dry at all times. At the processing facility, the potash salt $(\mathrm{KCl})$ will be separated from the waste salt $(\mathrm{NaCl})$, dried, stored, and then loaded onto barges for transhipment to ocean-going vessels using a custom-built jetty facility. The waste salt will be pre-diluted and then discharged into the ocean.

A comprehensive trade-off study of all transport solutions was conducted in the early stages of the prefeasibility study (PFS). This paper describes the methodology followed to select the materials transport system for

\footnotetext{
* Kore Potash Limited.

+ Centre for Sustainability in Mining and Industry, University of the Witwatersrand, South Africa.

(C) The Southern African Institute of Mining and Metallurgy, 2017. ISSN 2225-6253. Paper received Nov. 2015; revised paper received Jun. 2016.
} 


\section{Ore transport system selection for the Sintoukola potash project in the Republic of Congo}
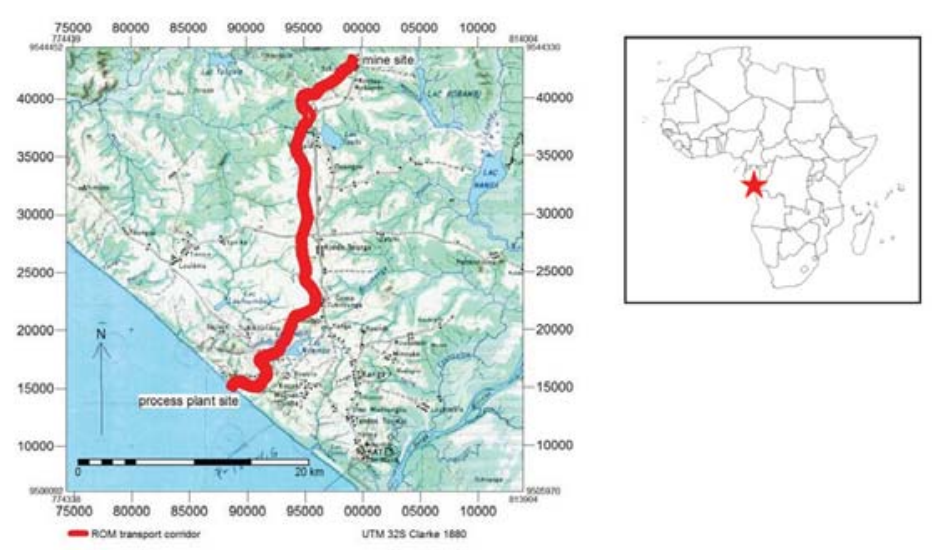

Figure 1-Location map

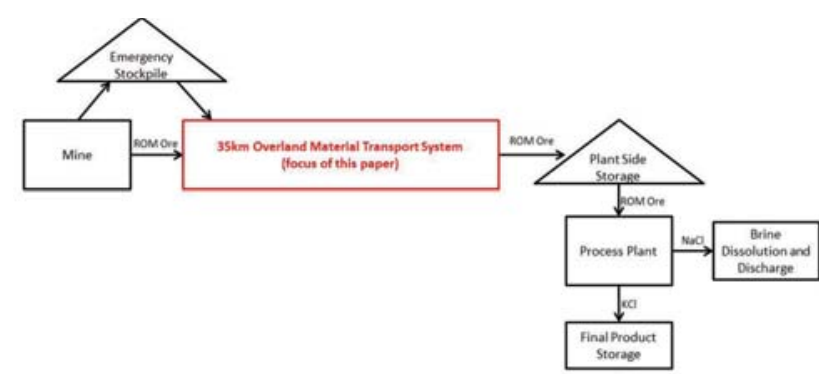

Figure 2-A simple diagram showing the material storage and transport segments

moving the ROM ore from the mine site to the process plant. The selection of the materials transport system was undertaken subsequent to the PFS and in preparation for the feasibility study (FS), based on new fieldwork data that had become available.

\section{Bulk ore transport}

For bulk commodity mines, ore transport is particularly critical as it commonly constitutes a significant component of overall capital and operating costs. Generally, the materials handling component makes up 30-75\% of a mine's operating cost (Karande and Chakraborty, 2013). In Central Africa, as in many developing regions, mineral projects have to invest substantially in establishing transport infrastructure. Existing infrastructure is frequently over-utilized, has poor levels of availability, and/or is not fit for purpose. Consequently, selecting the ore transport system for the Sintokoula potash project is crucial to the project's viability.

The PFS for the project was completed in 2012 and recommended a fleet of road-train haul trucks using a dedicated haul road. The haul road system was selected after a comprehensive trade-off study conducted in mid-2011, which considered conveyors, rail, road, and a pipeline for material transport in combination with different plant locations and layouts. Rail and conveyors were initially discarded on account of their high upfront capital costs, while the pipeline was eliminated for operability reasons.

After the completion of an on-site geotechnical investigation programme, it became apparent that the costs of haul road construction were significantly underestimated during the original trade-off study. In addition, an independent review of the PFS indicated that the costs for overland conveyors may have been overestimated. According to Saxby and Elkink (2010), the operating costs of conveyor belts for distances between 25 and $40 \mathrm{~km}$ should be approximately $20 \%$ of those of truck transport. These authors reported that single-flight conveyor lengths increased from around $5 \mathrm{~km}$ to $20 \mathrm{~km}$ between 1985 and 2005 . Consequently, fewer flights, with reduced re-handling of ore, are required to cover large distances. This trend has significantly improved the competitiveness of conveying systems.

In addition, with the completion of the Environmental and Social Impact Assessment (ESIA), a better understanding of the social and health and safety context of the area highlighted the risks inherent in an around-the-clock road hauling operation. It was therefore decided to revisit the material transport system selection in 2013, by comparing an overland conveyor option to the PFS road hauling option.

\section{Transport system selection}

There are numerous factors to consider when selecting a transport system. Karande and Chakraborty (2013, p. 2) list criteria such as 'better utilization of manpower, providing product flexibility, increasing productivity, decreasing lead time, reduction in handling cost, increased efficiency of material flow, and enhancement of production process' as just some of the criteria to consider. They emphasize that the decision-making process should use a multi-criteria analysis approach.

Many complex analytical methods, such as the analytical hierarchical process, exist for this type of multi-criteria decision-making, and the applications in the mining industry have been described by Kluge and Malan (2011), among others. Owusu-Mensah and Musingwini (2011) elaborate on how this method was used to select an ore transport system for a lower tonnage at a Ghanaian gold mine. The emphasis in this paper, however, is on explaining a simply weighted multi-criteria process that can be more easily and simply applied in a project setting, without the use of complex matrix algebra or other tools and systems.

Pratt (2008) suggests that the assessment of materials transport systems focuses on the following fundamental questions:

- How reliable are they? What is the degree of technical risk in a business context? 


\section{Ore transport system selection for the Sintoukola potash project in the Republic of Congo}

What levels of flexibility do they offer?

How capital-effective are they? What returns are indicated by the balance of capital and operating cost estimates?

In modern mining practice, environmental, and social impacts of projects must also be considered alongside the traditional technical and economic considerations when optimizing projects - bulk ore transport systems have the potential for high environmental and social impacts.

For the Sintoukola project, the selection of the transport system was based on:

> Minimizing capital and operating costs over the working life of the system

> Optimizing operability of the system

> Minimizing environmental consequences of operation of the system

> Maximizing environmental benefits of the system alignment

> Minimizing safety risks of system operation.

Consequently, the project team decided to follow a threepronged approach in assessing the transport system:

> Operability: the criteria listed by Karande and Chakraborty (2013) and the questions regarding reliability and flexibility proposed by Pratt (2008) were grouped into one category focused on the impact of the material transport system on the overall project system. This includes power, water, employees, stockpile sizing, availability, and maintenance

> Net present cost (NPC): as economic profitability and return on investment underlie all mining projects, it is important to consider the impact that the choice of transport system will have on project value. This includes an analysis of operating, capital, and sustaining capital costs, resulting in comparison on NPC terms

> Safety, health, and environment assessment: the focus here is to both identify 'show-stoppers', that immediately exclude a system from further consideration, and to weigh and compare those impacts that can be mitigated.

For the sake of simplicity, all three criteria used in the assessment were considered to be of equal importance. Each will now be discussed in turn. The focus of the trade-off study discussed below is to compare an overland conveyor belt with the PFS base case of using a fleet of 25 road-train trucks to transport RoM ore on a dedicated haul road.

\section{Operability assessment}

Two workshops were held with conveyor belt consultants, the project infrastructure engineers, and the owner's team, which included the authors of this paper. The objective was to determine the impact of switching from hauling to a conveyor on the overall project configuration, identify critical flaws, and assess the potential for reducing project complexity and improving the project operability and reliability. The following points were identified:

$>$ Fuel and power supply

> Backup power requirements

> Availability and maintenance
- Labour requirements

> Reduction in surface facilities

> Sizing stockpiles for system downtime

$>$ Scalability.

\section{Fuel and power}

Fuel supply logistics are considerably more complex for truck-based hauling. Fuel needs to be transported via tanker from Pointe Noire and special fuel storage and truck refuelling infrastructure needs to be provided. Although the cost benefit of reducing this infrastructure has not been accounted for in the NPC analysis, it results in an improvement in project operability.

The overland conveyor is expected to require between 3.5 MW and $5 \mathrm{MW}$ of installed power capacity. This increases the base case power demand for the project by between $6 \%$ and $9 \%$. The increase is considered small enough to not materially affect the design of the electrical reticulation system. Drives and booster drives can be readily powered from the planned transmission line connecting the mine site and process plant. The oil price is expected to be more volatile than the gas price (gas is used to generate electricity in the $\mathrm{RC}$ ), which also makes the conveyor option preferred.

The planned emergency power supply is insufficient to sustain operations in the case of a grid interruption. It is sized to ensure that personnel can be evacuated safely and that equipment can be responsibly shut down. If the preference is to shut down the overland conveyor only when it is empty, additional backup power will need to be considered. These possible additional costs have not been considered in the NPC analysis. This might lead to an increase in project complexity, if restarting with a loaded conveyor belt is not feasible.

\section{Availability, downtime, and maintenance}

Haul trucks are collectively expected to be available almost continually. The only major downtime can result from problems at the loading or offloading facility or a major interruption on the haul road. The two conveyors in series are expected to have a lower availability. Each conveyor has an availability of $94 \%$, resulting in a system availability of $88 \%$. The resulting lower capacity can be offset by increasing the design capacity of the belts and allowing for larger stockpiles. Furthermore, planned belt downtime should be scheduled to coincide with plant maintenance. Nevertheless, the increased stockpile requirements at the mine and plant lead to increased project complexity.

A large truck workshop is required to maintain the hauling fleet. The conveyor belt can be maintained by a smaller team with a smaller workshop. The exclusive presence of sand to a depth of $40 \mathrm{~m}$ provides poor geotechnical conditions for the construction of platforms, storage yards, and workshops. Reducing or eliminating the footprint of this infrastructure is therefore of great benefit to the operation. These costs savings have not been included in the NPC analysis, but this leads to a reduction in project complexity.

A tear on the belt will require 2-3 days' downtime to splice. Provision for downtime of up to a week has been made in the cost assumptions. At the mine site, when the storage is full, a temporary stockpile is available for 


\section{Ore transport system selection for the Sintoukola potash project in the Republic of Congo}

emergencies, so mining operations will not be interrupted. To ensure that no production interruptions occur at the plant site, a significantly larger dome or a warehouse, similar to that used for product storage, will need to be constructed. For this analysis it was assumed that two domes with total storage capacity of $120 \mathrm{kt}$ will be constructed. A reassessment of the planned stockpile sizing is recommended, to ensure that it is adequate. The requirement for larger stockpiles and the possibility of major production interruptions when using a conveying system increase the complexity of the project

\section{Scalability}

There is a possibility for an expansion of mine production in the future. A haul road is easily scalable, as additional trucks linearly increase transport capacity. However, both loading and offloading facilities will be operating at maximum capacity and thus need to be replicated to increase production.

Conveyor belts are designed for a fixed capacity and upscaling requires additional capital outlay for a second belt. However, the incremental cost for specifying a larger capacity belt at the design phase is relatively small. The capacity required for the current Sintoukola production is $1080 \mathrm{t} / \mathrm{h}$ while the cost estimates made for the project by two suppliers were based on $1600 \mathrm{t} / \mathrm{h}$ and $2400 \mathrm{t} / \mathrm{h}$ systems. It is suggested that a belt with larger capacity be installed from the outset. Production can then be increased when required without the outlay of additional capital. This implies that if a sufficiently large belt is installed initially, the conveyor belt actually increases the future operability in the case of a production expansion. The large operating cost advantages of a conveyor belt would then also be further enhanced.

\section{Labour}

The truck hauling option requires almost 100 staff, while the conveyor will require fewer than 40 . This reduces the strain on the employee facilities, as well as general overheads. These costs savings have not been included in the NPC analysis, but this leads to a reduction in project complexity, as fewer people need to be accommodated in the project camp.

The operability review could identify no major flaw with an overland conveyor. In fact, many project areas have reduced project complexity and improved operability with the use of a conveyor belt. The major factor that requires addressing is the correct sizing of the mine and process plant stockpiles, but allowance for larger stockpiles has been made in the NPC assessment.

\section{Economic analysis}

The cost comparison consists of capital, sustaining capital, and operating costs. Using these parameters a NPC comparison can be made. All costs discussed in this section are in US dollars.

\section{Capital costs for hauling}

The haul road capital costs form the basis for the cost comparison. The various components of the capital costs are listed in Table I.

> Fencing, earthworks and forest clearing, crossing culverts, and remoteness factor are explicitly costed for the conveyor options, but were included in direct capex for truck hauling

> The haulage option did not require additional service and access roads and did not require electrical installations

> The capital cost of the haul road is estimated to be $\$ 116$ million, with the trucks and trailers comprising an additional \$16 million.

> Loading and offloading includes the loading and offloading infrastructure as well as the associated product storage at the mine and process site. For the truck hauling option, the cost of these facilities is approximately $\$ 62$ million, which can be divided as follows:

- Storage at mine site: $\$ 12$ million

- Loading at mine site: \$25 million

- Offloading at process plant site: \$14 million

- Storage at process plant site: \$11 million.

> A contingency of $15 \%$ was used for the haul road and road trains

> Engineering, procurement, construction, and management (EPCM): $12.5 \%$ was used for the haul road as applied in the PFS

$>1.2 \%$ was used for insurance as per the PFS.

\section{Capital cost for overland conveyor}

The overland conveyor will be approximately $35 \mathrm{~km}$ long, will be fully covered, and for the purpose of this evaluation consists of two flights. Three estimates of conveyor costs, considered to be at a Class 5/41 level of accuracy, were supplied by three different suppliers and were used in this comparison. The capital costs are compared in Table I. The following assumptions were used for the individual line items.

Supplier 1 based the direct capex figures on a previous project database derived from a belt system consisting of three $11.7 \mathrm{~km}$ flights, with a capacity of $1600 \mathrm{t} / \mathrm{h}$ and a belt speed of $3.5 \mathrm{~m} / \mathrm{s}$. This system was estimated to cost $\$ 92$ million. Although the belt at Sintoukola will likely be configured in two flights, it was felt that this cost for a threeflight belt was comparable for this distance.

Supplier 2 based direct capex on a project in South Africa at the time of this study. A belt with a capacity of $2400 \mathrm{t} / \mathrm{h}$ and belt speed of $6.5 \mathrm{~m} / \mathrm{s}$ was costed at approximately $\$ 1769$ per metre or $\$ 83$ million. Supplier 3 provided the estimate prepared for the original trade-off study in 2011 at \$201 million. Fencing costs are based on the assumption that both sides are fenced for $35 \mathrm{~km}$ at $\$ 10$ per metre.

The haul road costs include a cost of $\$ 900000$ per kilometre for site clearance and earthworks. It was assumed that the costs for the conveyor will be $15 \%$ of these as a conveyor can accommodate significantly steeper angles and therefore requires less cut and fill. This was confirmed in an independent assessment by an engineering company, who estimated the earthworks requirements and costs if a conveyor was superimposed on the haul road corridor. Their estimated cost of approximately $\$ 2$ million for earthworks is in the same order of magnitude as the 15\% factor applied.

${ }_{1}$ AACE International Recommended Practice No. 18R-97 


\section{Ore transport system selection for the Sintoukola potash project in the Republic of Congo}

The cost of the service road was estimated as $\$ 3.5$ million by the project infrastructure consultants. This equates to $\$ 100000$ per kilometre. With the conveyor option, there will be no haul road to provide vehicle access to the process plant and mine site, and an additional $14 \mathrm{~km}$ of access road must be constructed at a cost of $\$ 2$ million per kilometre.

The haul road costs include $\$ 70000$ per kilometre for crossing culverts. It was assumed that the costs for the conveyor will be $50 \%$ of these, as conveyor crossings are comparatively simple.

Each of the two belts will have a booster drive, which means a total of four drives is required. As one drive will be located at the process plant site, three take-offs from the overhead line with associated infrastructure are required. These were estimated to cost $\$ 5$ million in total.

The 'remoteness allowance' attempts to capture the additional cost of construction in the RC rather than South Africa. This is mostly as a result of higher transport, concrete, and supervision costs.

Loading and offloading costs include the loading and offloading infrastructure as well as the associated product storage at the mine and plant site. As the loading and offloading arrangements for the conveyor are expected to be much simpler than for the road trains, these costs can be reduced. Storage at the plant site will need to be increased significantly due to lower system availability for a conveyor compared to a haul truck fleet. For the conveyor option, the loading/offloading cost is $\$ 50$ million, which can be divided as follows:

> Storage at mine site: $\$ 12$ million

$>$ Loading at mine site: $\$ 5$ million

> Offloading at process plant site: $\$ 3$ million

> Storage at process plant site: $\$ 30$ million.

Given the higher level of uncertainty in the conveyor costs, a contingency of $20 \%$ was used. An EPCM cost of $10 \%$ was recommended for the conveyor belt by the suppliers. $1.2 \%$ was used for insurance as per the PFS.

It can be seen from Table I that the capital cost estimates provided by suppliers 1 and 2 are similar and only marginally higher than those for the hauling option. The original conveyor capex estimate used in the first trade-off study is approximately $\$ 90$ million higher.

The following capital savings on the PFS cost estimate resulting from the installation of an overland conveyor were not considered here:

> Smaller workshop footprint and requirements

> Savings on the employee facilities due to a smaller workforce

> Reduced fuel farm requirements and refuelling facilities

> Reduced earthworks at mine and process plant site, no turning loops, and smaller loading and offloading infrastructure.

\section{Sustaining capital}

The sustaining capital is shown in Table II. Sustaining capital for the truck hauling option consists mainly of maintaining the drainage systems and the relaying of tarmac on the haul road as well as infrequent truck fleet replacements. A factor of $2 \%$ on initial capital, as recommended by Saxby and Elkink (2010) was used to determine annualized sustaining capex on the conveyors.

The sustaining capital costs are considerably higher for the conveyors, which can be expected given the increased amount of mechanical and electrical equipment.

\section{Operating costs}

Annual operating costs of the truck hauling option at steady state are $\$ 27.6$ million, which is made up of the following:

$>\$ 0.07$ per ton loading facility

Table I

\section{Comparison of capital costs (\$ thousand)}

\begin{tabular}{|c|c|c|c|c|}
\hline Option & Hauling & Conveyor Supplier 1 & Conveyor Supplier 2 & Conveyor Supplier 3 \\
\hline $\begin{array}{l}\text { Direct capex } \\
\text { Fencing } \\
\text { Earthworks and forest clearing } \\
\text { Service road } \\
\text { Access road } \\
\text { Crossing culverts } \\
\text { Electrical } \\
\text { Remoteness allowance } \\
\text { Loading and offloading } \\
\text { Contingency } \\
\text { EPCM } \\
\text { Insurance } \\
\text { Total initial capex }\end{array}$ & $\begin{array}{l}115664 \\
\text { Included } \\
\text { Included } \\
\text { Not required } \\
\text { Not required } \\
\text { Included } \\
\text { Not required } \\
\text { Included } \\
63135 \\
26820 \\
25702 \\
2467 \\
233789\end{array}$ & $\begin{array}{c}92000 \\
700 \\
4725 \\
3500 \\
27440 \\
1225 \\
5000 \\
5000 \\
50000 \\
37918 \\
22751 \\
2730 \\
252989\end{array}$ & $\begin{array}{c}82539 \\
700 \\
4725 \\
3500 \\
27440 \\
1225 \\
5000 \\
5000 \\
50000 \\
36026 \\
21616 \\
2594 \\
240365\end{array}$ & $\begin{array}{l}201600 \\
\text { Included } \\
\text { Included } \\
\text { Included } \\
\text { Included } \\
\text { Included } \\
\text { Included } \\
\text { Included } \\
40000 \\
48320 \\
28992 \\
3479 \\
322391\end{array}$ \\
\hline
\end{tabular}

Table II

Comparison of sustaining capital costs (\$ thousand per annum)

\begin{tabular}{|l|c|c|c|}
\hline Option & Hauling & Conveyor Supplier 1 & Conveyor Supplier 2 \\
\hline Sustaining capex (LoM) & 36400 & Conveyor Supplier $\mathbf{3}$ & \\
Sustaining capex (\$ thousand per annum) & 1820 & 5060 & 4807 \\
\hline
\end{tabular}




\section{Ore transport system selection for the Sintoukola potash project in the Republic of Congo}

$>\$ 2.85$ per ton haul truck operations and maintenance

$>\$ 1.12$ per ton haul road maintenance.

Supplier 3 estimated the operating costs of the conveyor system at just under $\$ 4$ million per annum. Supplier 1 estimated the operating cost for three conveyors in series at $\$ 0.67$ per ton, resulting in an opex of $\$ 4.5$ million per annum. Calculating the operating costs from first principles results2 in a cost of $\$ 4.2$ million per annum. This was used for the supplier 2 option. From Table III it is apparent that the operating cost estimates by the various suppliers, as well as those derived from first principles, lie in a narrow range. These costs are also in agreement with the assertion by Saxby and Elkink (2010) that conveyor operating costs for these distances should be approximately $20 \%$ of those for trucking.

\section{NPC comparison}

Using the cost inputs discussed above, a NPC analysis based on a discount rate of $10 \%$ was used to assess the total costs of the material transport systems. The base year was 2013. The results are shown in Table IV and in the plot of cumulative NPC values in Figure 3.

An improvement of between $\$ 125$ million and $\$ 140$ million in NPV is possible by changing from hauling to conveying. Even using the supplier 3 estimate that was deemed 'conservative' results in a better NPV than hauling.

\section{Environmental, health, safety, and social analysis}

A desktop assessment comparing the potential impacts and risks associated with the road-train trucking option and overland conveyors was undertaken to complement the technical and economic assessments. Four categories were used: environment, health and safety, social impacts, and closure. Sub-categories were weighted according to importance. A weight of 1 was assigned to sub-categories of low importance and a weight of 3 to critical sub-categories. The performance of the two modes of transport was then compared in each sub-category with poor performance attracting a score of 1 and excellent performance a score of 3 . These scores were multiplied by the weighting to obtain the weighted scores, which were summed to determine the overall relative performance in each category. These results are presented below.

\section{Environmental performance}

Belt conveyors operate relatively quietly and dust is an issue only at loading and discharge points, where it can be contained and dealt with (Unmacht and Alspaugh, 2009). Measured sound levels for conventional belt conveyors transporting $10000 \mathrm{t} / \mathrm{h}$ at $5 \mathrm{~m} / \mathrm{s}$ in the coal industry range 3 between $113 \mathrm{~dB}(\mathrm{~A})$ and $119 \mathrm{~dB}(\mathrm{~A})$ per $100 \mathrm{~m}$ of length. 'Low-noise' conveyors operate at levels down to $101 \mathrm{~dB}(\mathrm{~A})$ per 100 m (Brown, 2004). For Rio Tinto's Simandou project, sound pressure levels of $119 \mathrm{~dB}(\mathrm{~A})$ were reported for Komatsu haul trucks and $117 \mathrm{~dB}(\mathrm{~A})$ for Cat 777 trucks. The sound pressure levels expected for the road trains would be lower than these figures. $24 \mathrm{MW}$ power, 30 local employees, 3 expats, 5 vehicles, $3 \%$ of
mechanicals for spares
3 This is an order of magnitude greater than the mass flow rate for
Sintoukola.

\section{Table III}

\section{Comparison of operating costs (\$ thousand per annum)}

\begin{tabular}{|l|c|c|c|}
\hline Option & Hauling & Conveyor Supplier 1 & Conveyor Supplier 2 \\
\hline Opex (\$ thousand per annum) & 27674 & 4590 & 4200 \\
\hline
\end{tabular}

Table IV

\section{Comparison of NPC (\$ thousand)}

\begin{tabular}{|l|c|c|c|}
\hline Option & Hauling & Conveyor Supplier 1 & Conveyor Supplier 2 \\
\hline NPC & 410394 & 287428 & 271956 \\
\hline
\end{tabular}

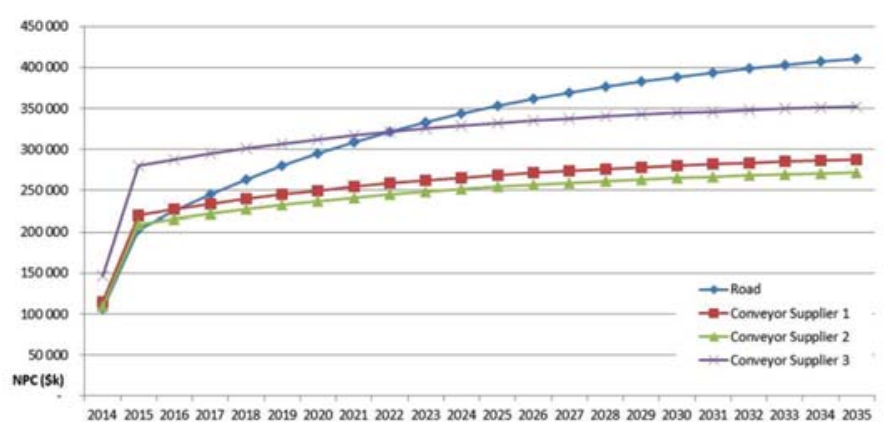

Figure 3-NPC analysis of the various options (\$ thousand) 


\section{Ore transport system selection for the Sintoukola potash project in the Republic of Congo}

Carbon dioxide $\left(\mathrm{CO}_{2}\right)$ emissions from a belt transport system are reduced by factors in the range $1.2-1.4 \mathrm{~kg} / \mathrm{t} . \mathrm{km}$ relative to truck haulage (Raaz and Mentges, 2011). For a distance of $35 \mathrm{~km}$ and an annual production of $6.9 \mathrm{Mt}$, this equates to a potential reduction in $\mathrm{CO}_{2}$ emissions of 289800 to $338140 \mathrm{t}$ annually. The relative environmental performance of the two systems is summarized in Table $\mathrm{V}$.

\section{Health and safety performance}

Belts can be monitored and operated remotely from a central control room, removing operators from possible risk areas (Unmacht and Alspaugh, 2009). There will be reduced risk of night-time accidents as other users will not be able to utilize the conveyor route to the degree possible with a haul road. Pedestrians are at risk with the haul truck option to a greater degree than with the overland conveyors. The potential risks of unauthorized access are consequently lower.

Conveyor belts require a significant amount of heat to commence combusting, but once ignited, the fire cannot easily be controlled (le Roux, 2004). Belts are likely to be capable of self-sustained combustion (Table VI).

\section{Social performance}

A disadvantage from a social perspective is that conveyor systems are less labour-intensive than trucks and require only one person per $\mathrm{km}$ for operation 4 . This equates to approximately 40 people for a belt versus more than 100 for the truck option. This disadvantage is offset by the lower potential social impacts (Table VII).

\section{Closure}

Overland conveyors can accommodate steeper gradients than road trains and thus the need for cut and fill is reduced. Current conveyor technology can tolerate inclines of up to $35^{\circ}$, while haul trucks are limited to gradients of not much more than $5^{\circ}$ (Metzger, 2007; Unmacht, and Alspaugh, 2009). While a more realistic maximum incline for an overland conveyor is probably around $12^{\circ}$, this still represents a significant reduction in cut and fill volumes required and thus a reduced rehabilitation footprint on closure. Conveyors are also able to curve in the horizontal plane and can avoid hills (Table VIII).

The contention that trucks have higher $\mathrm{CO}_{2}$ and dust emissions, suffer from more erratic labour costs (due to larger labour complements), have higher maintenance requirements (while conveyors have longer lifespans), and have high noise levels (Superior Industries, 2009) is supported by this study. In the comparative assessment, conveyors scored a total of 110 versus 62 for trucks. This represents a significant advantage over trucks from an environmental, social, and health/safety perspective.

4 Industry rule of thumb

Table $V$

Environmental criteria performance comparison (note higher risks obtain a lower score)

\begin{tabular}{|l|c|c|c|c|c|}
\hline \multirow{2}{*}{ Environmental aspects } & \multirow{2}{*}{ Weighting } & Belts & Trucks & Belts & Trucks \\
\cline { 3 - 6 } & & Score & Score & Weighted score & Weighted score \\
\hline Noise & 2 & 2 & 1 & 4 & 2 \\
\hline Dust/particulates & 3 & 3 & 3 & 9 & 9 \\
\hline Exhaust gases & 1 & 3 & 1 & 3 & 1 \\
\hline Carbon footprint & 1 & 3 & 1 & 6 & 2 \\
\hline Light pollution/visual intrusion & 2 & 3 & 1 & 6 & 2 \\
\hline Animal strike & 2 & 3 & 1 & 9 & 3 \\
\hline Spills (hydrocarbon/product) & 3 & 2 & 1 & 3 & 3 \\
\hline Land surface impact (cut and fill) & 3 & 3 & 49 & 1 \\
\hline Hydrocarbon logistics & 1 & 3 & & & 24 \\
\hline Sub-total & & & & & \\
\hline
\end{tabular}

${ }^{*}$ Assuming that the belt is not illuminated

Table VI

Health and safety criteria performance comparison (note higher risks obtain a lower score)

\begin{tabular}{|c|c|c|c|c|c|}
\hline \multirow[t]{2}{*}{ Health and safety aspects } & \multirow[t]{2}{*}{ Weighting } & Belts & Trucks & Belts & Trucks \\
\hline & & Score & Score & Weighted score & Weighted score \\
\hline Risk of accident and injury & 3 & 2 & 1 & 6 & 3 \\
\hline Risk of unauthorised access & 3 & 3 & 1 & 9 & 3 \\
\hline Night operation & 2 & 3 & 1 & 6 & 2 \\
\hline Driver fatigue & 2 & 3 & 1 & 6 & 2 \\
\hline Fire & 3 & 1 & 2 & 3 & 6 \\
\hline \multicolumn{4}{|l|}{ Sub-total } & 30 & 16 \\
\hline
\end{tabular}




\section{Ore transport system selection for the Sintoukola potash project in the Republic of Congo}

\begin{tabular}{|c|c|c|c|c|c|}
\hline $\begin{array}{l}\text { Table VII } \\
\text { Social criteria performance }\end{array}$ & parison ( $n$ & risks & ower s & & \\
\hline Social aspects & Weighting & Belts & Trucks & Belts & Trucks \\
\hline & & Score & Score & Weighted score & Weighted score \\
\hline Control of access to the national park & 3 & 3 & 2 & 9 & 6 \\
\hline Social disruption (village migration) & 3 & 3 & 1 & 9 & 3 \\
\hline Employment & 3 & 1 & 3 & 3 & 9 \\
\hline Ease of underpass construction & 2 & 2 & 1 & 4 & 2 \\
\hline Sub-total & & & & 25 & 20 \\
\hline
\end{tabular}

Table VIII

Closure criterion performance comparison (note higher risks obtain a lower score)

\begin{tabular}{|c|c|c|c|c|c|}
\hline \multirow[t]{2}{*}{ Closure aspects } & \multirow[t]{2}{*}{ Weighting } & Belts & Trucks & Belts & Trucks \\
\hline & & Score & Score & Weighted score & Weighted score \\
\hline Removal of infrastructure & 2 & 3 & 1 & 6 & 2 \\
\hline \multicolumn{4}{|l|}{ Sub-total } & 6 & 2 \\
\hline
\end{tabular}

\section{Summary and conclusion}

This paper presented a three-criterion methodology for assessing a mine transport system. The methodology was then demonstrated on a case study assessment of truck hauling vS overland conveyor belt for the Sintoukola potash project in the Republic of Congo. Table IX summarizes the performance of the two considered transport methods for the three considered criteria.

With similar capital costs, but significantly lower operating costs, the NPC analysis showed that an overland conveyor belt should be clearly preferred over a fleet of haul trucks for this application. The improvement in project value is expected to be between $\$ 125$ million and $\$ 140$ million.

During two workshops, no major critical flaws could be identified with the overland conveyor. Some project component complexity is increased, while in other areas operational improvements can be realized as a result of an overland conveyor.

An assessment based on environmental, health and safety, social, and closure factors was undertaken with specific focus on comparing trucks and conveyor belt. The conveyor belt was preferred in all four aspects.

It was concluded by the project team that an overland conveyor should be preferred to the haul road, and this key change to the project configuration will be taken into the feasibility study.

\section{References}

BRown, S.C. 2004. Conveyor noise specification and control. Proceedings of Acoustics 2004, Gold Coast, Australia, 3-5 November. Mee, D.J., Hooker, R.J., and Hillock, I.D.M. (eds.). Australian Acoustical Society.

pp. 269-276.

KARANDE, P. and CHAKRABORTY, S. 2013. Material handling equipment selection using weighted utility additive theory. Journal of Industrial Engineering, vol. 2013, Article ID 268708.

KLUGE, P. and MALAN, D.F. 2011. The application of the analytical hierarchica process in complex mining engineering design problems. Journal of the Southern African Institute of Mining and Metallurgy, vol. 111, no. 12. pp. 847-855.

Le Roux, H. 2004. Conveyors come under scrutiny after Northam Platinum mine fire. Mining Weekly, 29 October.

\section{Table IX}

Summary of all three criteria

\begin{tabular}{|l|c|c|}
\hline Criterion & Conveyor & Hauling \\
\hline $\begin{array}{l}\text { Operability } \\
\text { Fuel and power }\end{array}$ & Preferred & \\
Availability, maintenance & Preferred \\
Scalability & Preferred & \\
Labour & Preferred & \\
Economic analysis & $\$ 270 \mathrm{~m}-\$ 285 \mathrm{~m}$ & $\$ 410 \mathrm{~m}$ \\
Net present cost & Preferred & \\
\hline SHE Analysis & Preferred & \\
Environmental & Preferred & \\
Health and safety & Preferred & \\
Social & Preferred & \\
Closure & & \\
\hline
\end{tabular}

METZGER, D. 2007. Long distance conveying - long term savings. Technical Bulletin, Superior Industries LLC, Morris, MN. 7 pp.

Owusu-Mensah, F. and Musingwini, C. 2011. Evaluation of ore transport options from Kwesi Mensah Shaft to the mill at the Obuasi mine. International Journal of Mining, Reclamation and Environment, vol. 25, no. 2. pp. 109-125.

PRATT, A.G.L. 2008. Mine haulage - options and the process of choice, Proceedings of the Tenth Underground Operators' Conference, Launceston, Tasmania. Australasian Institute of Mining and Metallurgy, Melbourne. pp 179-188.

RAAZ, V. and MENTGES, U. 2011 Comparison of energy efficiency and CO2 emissions for trucks haulage vs in-pit crushing and conveying of materials. Proceedings of the SME Annual Meeting. Society for Mining, Metallurgy and Exploration, Inc., Littleton, CO. 6 pp.

SAXBY, P. and ELKINK, J. 2010. Material transportation in mining - trends in equipment development and selection. Australian Bulk Handling Review, March/April 2010.

Singh, M.M. and SAPERSTEIN, L.W. 1992. Production operations. SME Mining Engineering Handbook, 2nd edn. Vol.1. Hartman, H.L. (ed.). Society for Mining, Metallurgy and Exploration, Inc., Littleton, CO, USA. pp 677-802.

SUPERIOR INDUSTRIES. 2009. Overland conveyor systems. Superior Industries LLC, Morris, MN. 4 pp.

Unmacht, D. and Alspaugh, M. 2009. Harnessing gravity - the new rock conveying system planned for National Cement's Lebec plant. https://www.worldcement.com/magazine/world-cement/may-2009/ $4 \mathrm{pp}$. 